\title{
Metal-Salen-based Probes for the Selective Detection of Phosphates via a Disassembly Approach
}

\author{
Prerna Yadav§ and Felix Zelder* \\ §SCS-DSM Award for best poster presentation in Analytical Sciences
}

\begin{abstract}
Polyoxophosphates are ubiquitous in nature and play important roles in biological systems and in the environment. Pyrophosphate (PPi), an important member of this family, is produced in over 200 biochemical reactions and is a marker in clinical diagnosis. In addition to its endogenous role, PPi alias E450 is currently used as preservative, emulsifier or taste intensifier in foodstuff. Despite this widespread occurrence and biological importance, it is rather surprising that robust chemical systems that detect selectively and sensitively PPi in challenging matrices are still lacking. This mini review focuses on metal-salen complexes as reaction-based fluorescent sensors for the selective detection of PPi and other phosphates. The mode of detection is based on a novel disassembly approach in which the metal ion is sequestered by the target analyte from the complex and the metal-free ligand hydrolyses spontaneously into its fluorescent subunits. Optimizations of the probe and applications for PPi detection in cells and foodstuff are described.
\end{abstract}

Keywords: Cell studies · Disassembly approach · Foodstuff · Phosphates · Salen complex

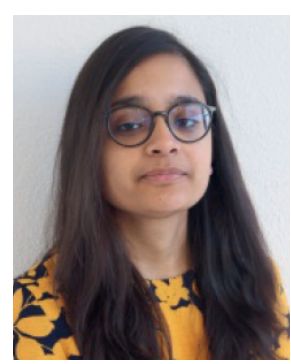

Prerna Yadav was born in Madhya Pradesh in India. She moved to National Institute of Science Education and Research (NISER) in Odisha, to the East of India for her Integrated Master's degree programme. She was awarded her Master's degree in 2016. Then, she decided to move to Switzerland for her doctoral studies in 2017. She is currently working in the group of Prof. Felix Zelder at University of Zurich (UZH). Her project focuses on synthesis and modifications of metal complexes for selective analyte detection. Apart from the scientific work, she finds dancing and body combat exciting.

\section{Introduction}

Polyoxophosphates (Fig. 1) play a vital role in biological systems and in the environment. ${ }^{[1,2]}$ Along with their role in energy storage and signaling in living systems, phosphodiester bonds link the sugar base building blocks in deoxyribonucleotides, the molecules of life. ${ }^{[2]}$ In ecosystems, phosphate containing detergents and fertilizers contribute to the eutrophication of natural water resources resulting in a problematic increase in algae formation on the surface of water bodies. ${ }^{[3]}$ This behavior has become one of the leading causes of impairment of freshwater sources. ${ }^{[4]}$

Phytic acid (Fig. 1) represents the major storage form of phosphorous in plant seeds. ${ }^{[5-7]}$ It is an important food additive for ruminant livestock that is able to cleave enzymatically the phosphodiester bonds of phytic acid to phosphate and phosphorylated inositol derivatives. In contrast to this life-supporting role, it represents a toxic anti-nutrient for non-ruminants lacking this hydrolytic enzymatic activity. ${ }^{[7,8]}$

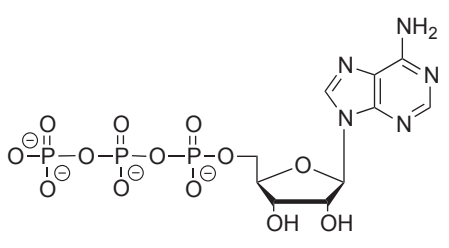

Adenosine triphosphate (ATP)

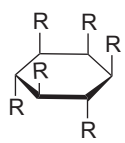

$\mathrm{R}=\mathrm{OPO}_{3}{ }^{2-}$

Phytic acid

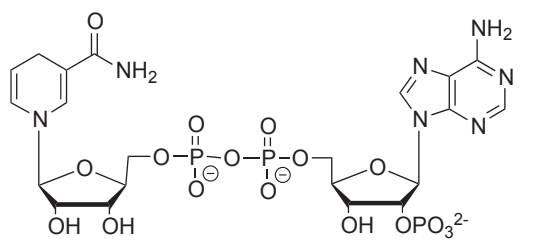

Nicotinamide adenine dinucleotide phosphate (NADPH)

Fig. 1. Structures, names and abbreviations of selected relevant polyoxophosphates.

Inorganic pyrophosphate (PPi; Fig. 1) is generated in more than 200 enzymatic reactions including the DNA polymerase chain reaction and the hydrolysis of adenosine triphosphate (ATP; Fig. 1) to PPi and adenosine monophosphate (AMP). ${ }^{[9]}$ Fluctuations in intracellular and extracellular levels of $\mathrm{PPi}$ are therefore indicative for certain diseases. ${ }^{[9]}$ In fact, PPi represents an important biological marker for crystal deposition disease, gout and cancer. ${ }^{[10-12]}$ In addition to its biological role, PPi is used as food additive E450 in the European Union. Examples of foodstuff with high diphosphate contents include nuts $(500 \mathrm{mg} / 100 \mathrm{~g})$ and baking powder $(1500$ $\mathrm{mg} /$ package). ${ }^{[13]}$ The recommended dietary intake of E450 should 
not exceed $70 \mathrm{mg}$ per kg of bodyweight and day. ${ }^{[14]}$ Although there seems to be no risk on phosphate intake for healthy people; hyperphosphatemia, a disorder with elevated levels of phosphates in the blood stream $(>1.45 \mathrm{mM})$, has become an increasing concern for patients with cardiovascular and chronic kidney diseases. ${ }^{[13,15,16]}$

Considering the widespread occurrence and important roles of PPi in different settings, the selective and sensitive detection of PPi has attracted much attention. Despite notable progress in this area, the selective detection of low concentrations of PPi $(<3 \mu \mathrm{M})$ in the presence of high concentrations $(>1 \mathrm{mM})$ of mixtures of other endogenous polyoxophosphates represents an analytical challenge. ${ }^{[17-20]}$

Some sensitive enzymatic assays for the detection of PPi are available, but they are only applicable for biological testing after cell destruction, isolation and purification. ${ }^{[21,22]}$ In contrast to bioassays, efficient chemical probes for selective and sensitive detection of PPi and other polyoxophosphates in biological, environmental and other challenging matrices are rare. ${ }^{[18,20,23,24]}$

In this mini review, we give a short overview over the field and then focus mainly on the contributions of the authors' research group to this important area. ${ }^{[20,25,26]}$

\section{Different Approaches towards Detection of PPi}

$\mathrm{H}_{4} \mathrm{PPi}\left(\mathrm{H}_{4} \mathrm{P}_{2} \mathrm{O}_{7}\right)$ is a four-proton donor with $\mathrm{p} K_{\mathrm{a}}$ values of 0.85 , 1.96, 6.60 and 9.41. ${ }^{[27]}$ At physiological $\mathrm{pH}$ of 7.4, $\mathrm{PPi}$ is therefore encountered as a mixture of $\mathrm{H}_{2} \mathrm{P}_{2} \mathrm{O}_{7}{ }^{2-}(14 \%)$ and $\mathrm{HP}_{2} \mathrm{O}_{7}{ }^{3-}(86 \%)^{[28]}$ and exhibits the ability to strongly chelate with metal cations. ${ }^{[29]}$ Depending on the transition metal ion, monomeric (M: $\mathrm{Fe}^{\mathrm{III}}, \mathrm{Cr}^{\mathrm{III}}$, $\left.\mathrm{Co}^{\mathrm{III} / \mathrm{II}}, \mathrm{Ni}^{\mathrm{II}}, \mathrm{Cu}^{\mathrm{II}}, \mathrm{Pt}^{\mathrm{IV}}\right),{ }^{[29-34]}$ dimeric $\left(\mathrm{M}: \mathrm{Zn}^{\mathrm{II}}, \mathrm{Mn}^{\mathrm{II}}, \mathrm{Pt}^{\mathrm{II}}\right),{ }^{[34-36]}$ tetrameric $\left(\mathrm{M}: \mathrm{Cu}^{\mathrm{II}}, \mathrm{VO}^{\mathrm{II}}, \mathrm{Zn}^{\text {III }}\right)^{[37-39]}$ and polymeric $\left(\mathrm{M}: \mathrm{Co}^{\mathrm{II}}\right)^{[40]}$ coordination complexes have been characterized by X-ray crystallography. Binding of PPi in biological systems is achieved by various interactions. ${ }^{[41]}$ In the active site of yeast pyrophosphatase (PPase; Fig. 2), PPi is coordinated to two Mn(II) ions and stabilized by additional hydrogen bonding and anion-cation interactions (Fig.

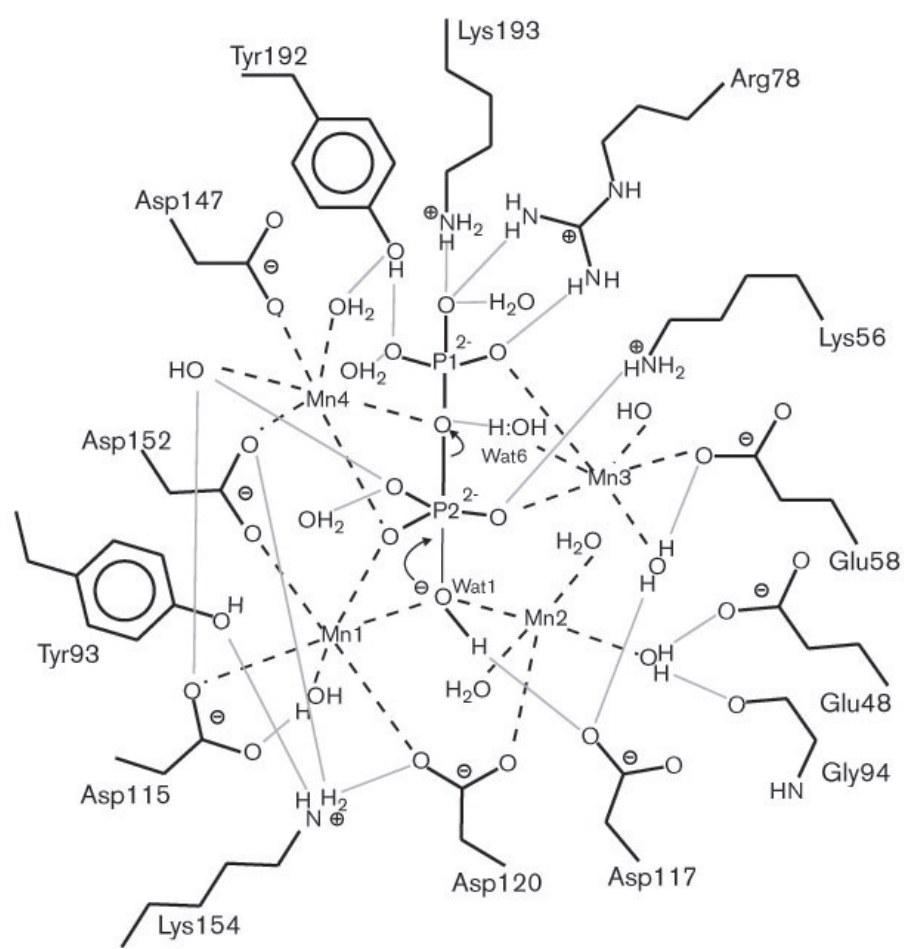

Fig. 2. Schematic representation of the active site of yeast pyrophosphatase (PPase) with bound PPi depicting Mn"-ligand coordination as well as hydrogen bonding and electrostatic interactions (Reprinted from P. Heikinheimo, J. Lehtonen, A. Baykov, R. Lahti, B. S. Cooperman, A. Goldman, 'The structural basis for pyrophosphatase catalysis', Structure, 1996, 4, 1491, with permission from Elsevier). ${ }^{[41]}$
2). ${ }^{[18,23,41]}$ Artificial receptors and sensors display similar interactions. ${ }^{[23]}$ Receptors exhibiting solely hydrogen bonding interactions have been intensively studied, but seldom work in pure aqueous conditions. ${ }^{[24]}$ Probably the most promising approach for selective and sensitive detection of PPi is based on metal complexes with either one or two metal binding sites. ${ }^{[23,24]}$

Some prominent examples of such metal complexes either depicting distinct modes of action or exhibiting remarkable discriminatory effects are discussed in more detail in the following section. ${ }^{[18,23]}$ A special focus is given to a disassembly approach with metal-salen complexes. ${ }^{[20,25,26]}$

\subsection{Indicator Displacement Assay (IDA)}

In an IDA, an indicator is displaced from a receptor by a strongly binding competitive analyte leading to a detectable optical signal (Fig. 3, top). ${ }^{[42]}$ The relative ease of structurally and electronically fine-tuning the individual building blocks and subsequent self-assembling to a supramolecular system make IDAs highly attractive for analytical applications. In fact, IDAs have been used widely for detecting a large variety of different analytes including anions. ${ }^{[42]}$ One of the first examples for discriminating PPi over ATP (5-fold increase in emission intensity) was reported by Hong and coworkers in 2004 using a binuclear $\mathrm{Zn}^{\text {II-bis(2- }}$ pyridylmethyl)amine complex (Fig. 4).[43,44]

Based on this pioneering study, systems with similar $\mathrm{Zn}^{\mathrm{II}}-$ containing binding motifs were developed including cyclic peptidebased receptors introduced by Jolliffe and her group in 2006. ${ }^{[45]}$

\subsection{Chemosensor}

A chemosensor consists of a receptor that is covalently linked to a signaling unit. ${ }^{[46]}$ Selective binding of the target analyte to

Indicator Displacement Assay (IDA)

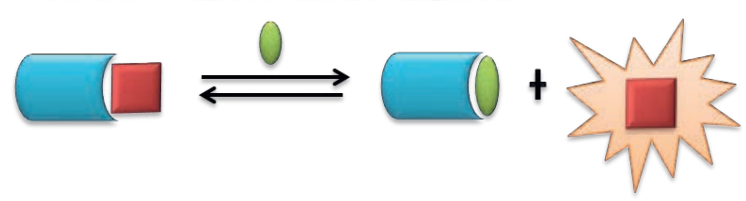

Chemosensor

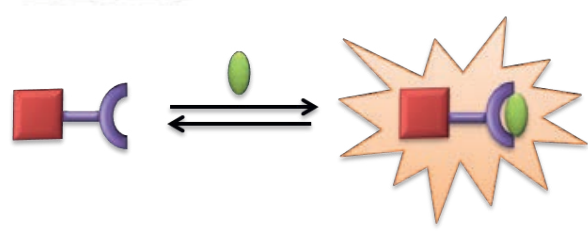

Fluorophore

: Analyte

Fig. 3. Schematic depiction of the mode of action of an indicator displacement assay (IDA; top) and a chemosensor approach (bottom).
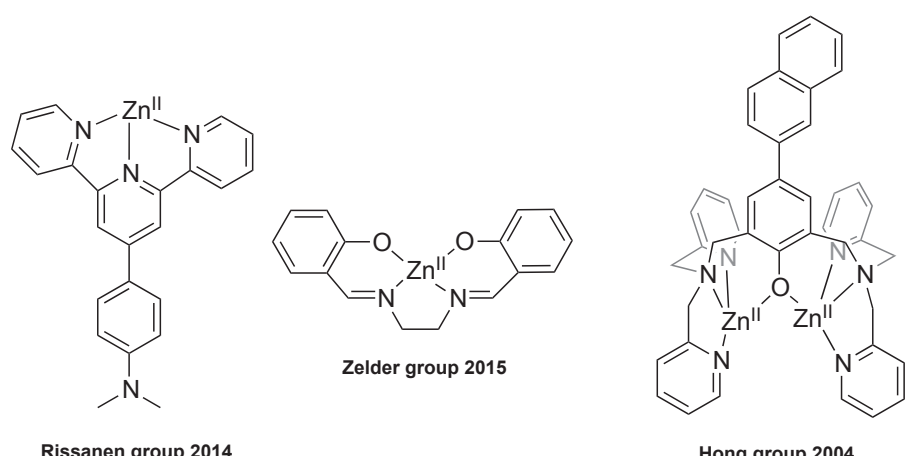

Fig. 4. Examples of $\mathrm{Zn} n$-based sensors for the detection of PPi.[26,43,48] 
the binding site leads to a colorimetric and/or a fluorometric detectable change (Fig. 3, bottom). A vast plethora of efficient systems for analytes including anions have been reported in the last decades. ${ }^{[46]}$ Probably the first example for the fluorometric detection of PPi in water ( $\mathrm{pH} 7$ ) was described by Czarnik using a polyamine-modified anthracene derivative. ${ }^{[47]}$ Strong binding of PPi to the receptor is based on a combination of electrostatic interactions and hydrogen bonding between analyte and the complementary polyamine. This molecular recognition event leads to a turn-on fluorescence of the anthracene signaling unit with a 2200-fold discrimination of PPi over phosphate $(\mathrm{Pi}){ }^{[47]}$ Rissanen and his group reported on the sensitive detection of PPi with a $\mathrm{Zn}^{\mathrm{II}}$-terpyridine complex (Fig. 4) leading to a 500-fold increase in fluorescence with an extraordinary limit of detection of $0.8 \mathrm{nM} \cdot{ }^{[48]}$

\subsection{Disassembly Approach}

The chemosensing and IDA approaches for PPi detection with metal complexes are based primarily on the binding of the target analyte to the metal center(s). In 2015, the Zelder group introduced a conceptually different and alternative strategy for polyoxophosphate detection. ${ }^{[26]}$ In this strategy, the target analyte translates into the disassembly of a metal complex into its molecular entities and a detectable fluorometric response.

In particular, the water-triggered hydrolysis of imine bonds (Fig. 5, pathway A) is initially prevented by metal chelation ('locked' complex; Fig. 5, pathway B) and is only triggered upon sequestration of the metal ion from the imine complex with the target analyte ('unlocking': Fig. 5, pathway C). The disassembly of the complex to the molecular building blocks leads to a colorimetric and/or fluorometric response. The concept of the disassembly approach is discussed in the following section in more detail. It was explicitly proven for polyoxophosphate detection with metal-salen complexes using numerous analytical techniques including UV-Vis, fluorescence spectroscopy, ${ }^{1} \mathrm{H}$ - and ${ }^{31} \mathrm{P}-\mathrm{NMR}$ as well as mass spectrometric studies. ${ }^{[25,26]}$

Although our group focuses momentarily mainly on polyoxophosphate detection with metal-salen complexes, ${ }^{[20,25,26]}$ the disassembly approach is not limited to this class of compounds as demonstrated earlier by Kim and coworkers for detecting toxic cyanide with a coumarin-based $\mathrm{Cu}^{\mathrm{II}}$ complex. ${ }^{[49]}$

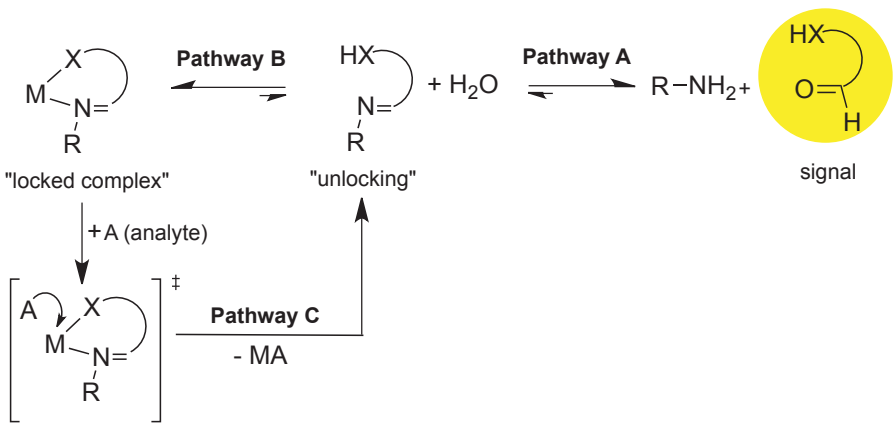

Fig. 5. Mode of analyte detection with metal-imine chelate complexes following the disassembly approach.

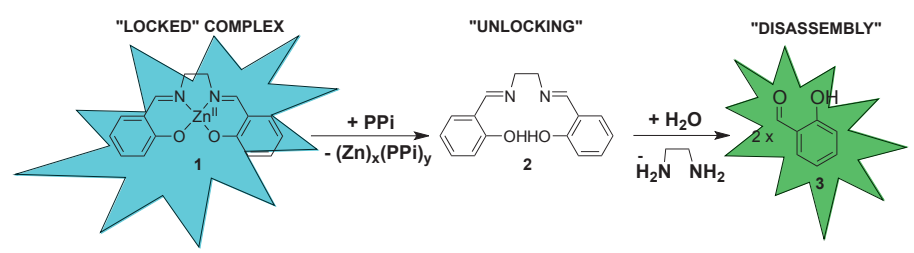

Fig. 6. Polyoxophosphate detection with the prototype $\mathrm{Zn}^{\prime \prime}$-salen complex. ${ }^{[26]}$

\section{Metal-Salen Complexes for Polyoxophosphate Detection}

\subsection{The Prototype}

Our group introduced in 2015 the concept of the disassembly approach with $\mathrm{Zn}^{\mathrm{II}}$-salen complexes for detecting di- and tri-phosphates at physiological pH 7.4 (Fig. 6). [26]

The disassembly of the blue fluorescent $\mathrm{Zn}^{\mathrm{II}}$-complex $\mathbf{1}$ ('locked complex'; $\lambda_{\text {em }}=467 \mathrm{~nm}$ ) by polyphosphates led to the metal-free salen ligand 2 ('unlocking') that hydrolyzed spontaneously to green fluorescent salicylaldehyde $\left(3 ; \lambda_{\mathrm{em}}=490 \mathrm{~nm}\right)$. Although the response was instantaneous, the discrimination between PPi and ATP was modest. In particular, an approx. 2.0 and 1.8 fold increase in emission intensity was observed for the former and latter analyte, respectively. Other drawbacks of this probe included the low fluorescence quantum yield (13\% in DMF) ${ }^{[50]}$ of the salicylaldehyde signaling unit as well as background hydrolysis of the complex.

For these reasons, we started a project to improve the properties of this compound by modulating the different subunits (Fig. 7) of the compounds systematically. Variations included modifications at the metal center (section 3.2), at the salicylaldehyde building block (section 3.3) and at the diamine backbone (section 3.4). Recent progress is described in the next section. ${ }^{[25,26]}$

\subsection{Effect of the Metal Center}

In light of search for selective probes for PPi, we decided to replace the central $\mathrm{Zn}^{\mathrm{II}}$ ion with other metal ions. In particular, we synthesized square pyramidal $\mathrm{Fe}^{\mathrm{III}}$ complexes with an apical water ligand for mainly two reasons. ${ }^{[20,25]}$ Incorporation of this metal ion instead of $\mathrm{Zn}^{\text {II }}$ into the salen framework results in a positive net charge and we expected additional electrostatic interactions between the analyte and the probe. Moreover, we anticipated that the combination of a hard Lewis acidic $\mathrm{Fe}^{\mathrm{III}}$ ion with a ligand framework of mixed Lewis base acidity would lead to stronger interactions and hence a better recognition of the rather hard polyoxophosphate anions. This assumption was proven to be correct and $\mathrm{Fe}^{\mathrm{III}}$-salen complex 4 (Fig. 7) was more selective for PPi over ATP and showed an approx. 180-fold turn on emission intensity compared to $\mathrm{Zn}^{\mathrm{II}}$ complex 1 (Fig. 6).[25]

\subsection{Modifications of the Salicylaldehyde Signaling Unit}

Modifications of the salicyaldehyde signaling unit were introduced for two reasons. In particular, we intended to improve selectivity and solubility. A sulfonate group was located at the para position of this building block to ensure water solubility of complex 5 (Fig. 7). This structural modification improved the quantum yield of the new salicylaldehyde signaling by a factor of 1.7 compared to the prototype signaling unit 3. ${ }^{[25,50]}$ An additional 2.7-fold increase of quantum yield of the salicylaldehyde signaling unit was achieved by introducing an additional chloride group at the ortho position in 6 (Fig. 7). ${ }^{[50]}$ Unfortunately, these signifi-

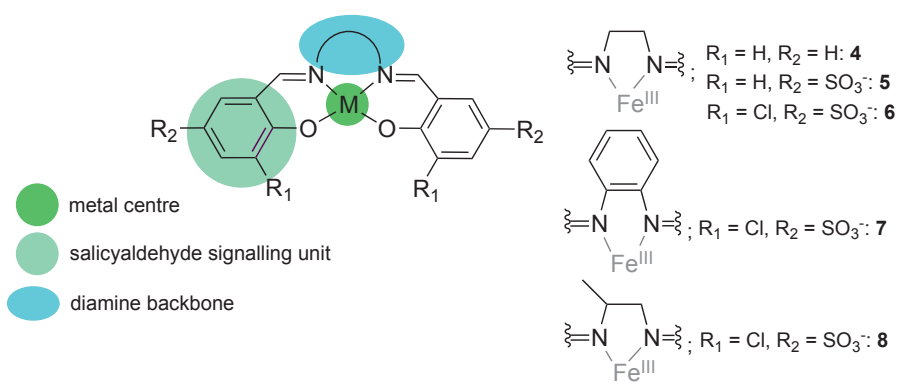

Fig. 7. Left: Metal-salen complexes and its molecular building blocks. Right: Fe'II-salen complexes with modifications of the diamine backbone and the salicylaldehyde building block. 
cant improvements in quantum yield were accompanied by a loss in selectivity of PPi over ATP and other phosphate anions. ${ }^{[20,25]}$

\subsection{Modifications of the Diamine Backbone}

After having observed that modifications of the salicylaldehyde building block had a significant negative impact on the selectivity of the probe, we speculated to counterbalance this undesired effect by modifications of the diamine backbone. Initially we tested modifications with either electron-withdrawing or electron-donating groups. ${ }^{[25]}$ For example $\mathrm{Fe}^{\mathrm{III}}$-salen complex 7 (Fig. 7) with a strongly donating phenylene diamine moiety did not show any disassembling behavior. ${ }^{[20,25]}$ Replacement of the latter diamine with a less donating 2-propanediamine backbone in 8 (Fig. 7) appeared then to represent an optimal sensor. ${ }^{[20]}$ A significant improvement in selectivity of complex $\mathbf{8}$ for PPi compared to $\mathbf{5}$ was achieved. In particular, 3.5-fold enhanced fluorescence emissions at $500 \mathrm{~nm}\left(\lambda_{\mathrm{ex}}=385 \mathrm{~nm}\right)$ with a limit of detection (LOD) of 1.50 $\mu \mathrm{M}$ was observed without interference from ATP, Pi and 14 other tested anions (Fig. 8).[20]

\subsection{The Disassembly Process}

The mechanism of the PPi-induced disassembly of metalsalen complexes has not yet been described on the molecular level, but initial results suggest formation of the metal-free ligand followed by fast hydrolysis into salicylaldehyde and the diamine subunit upon sequestration of the metal ion with the bidentate ligand PPi as schematically depicted in Fig. 5. This hypothesis is mainly supported from ${ }^{1} \mathrm{H}-\mathrm{NMR}$ experiments. In particular, the addition of 10 equiv. of PPi to the $\mathrm{Fe}^{\mathrm{III}}$-salen complex 8 in deuterated DMSO led to the formation of the metal-free salen ligand ('unlocking'; Fig. 5, pathway C). The latter hydrolyzed then rapidly into ethylenediamine and the salicylaldehyde derivative upon addition of deuterated water ('disassembly'; Fig. 5, pathway A). ${ }^{[20,25]}$ Formation of free salicylaldehyde from the complex was additionally confirmed by mass spectrometric studies. ${ }^{[20,25,26]}$ The demetallation ('unlocking') mechanism of the probe by PPi has not been described so far, but we assume that substitution of $\mathrm{Fe}^{\mathrm{III}}$-coordinated $\mathrm{H}_{2} \mathrm{O}$ by PPi is followed by sequestration of the metal ion as schematically depicted in Fig. 5 (pathway C). Detailed mechanistic studies are currently being undertaken in our laboratory.

\section{Applications of Metal-Salen Complexes for Selec- tive Detection of PPi in Living Cells and Foodstuff}

The applicability of metal-salen complexes for the selective detection of pyrophosphate was tested in living cells and food-

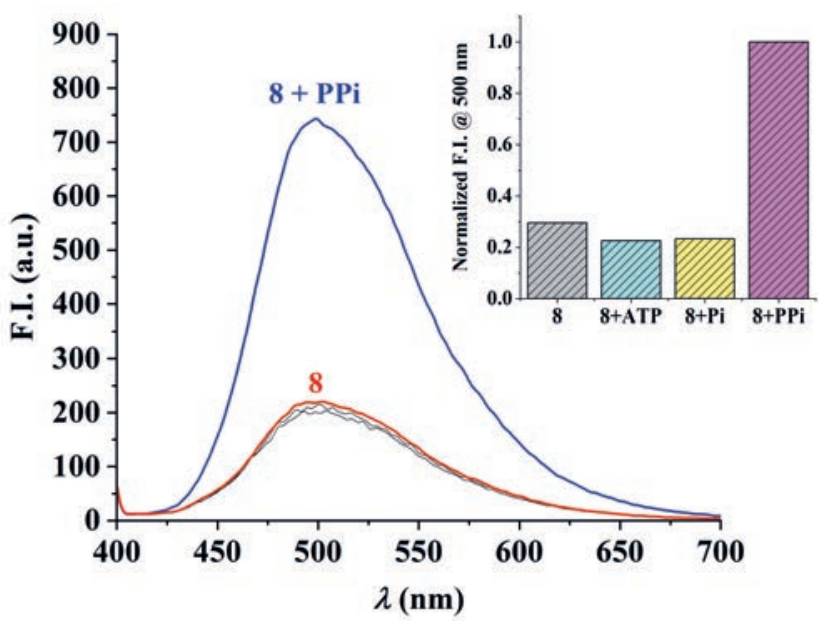

Fig. 8. Fluorescence spectra of $8\left(16 \mu \mathrm{M}, \lambda_{\text {ex }}=385 \mathrm{~nm}\right)$ in the presence of PPi (10 equiv), ATP (10 equiv) and Pi (10 equiv) at pH 7.4 ([Tris buffer] $=10 \mathrm{mM}$ ) incubated for $30 \mathrm{~min}$ (adapted from ref. [20]). stuff. ${ }^{[20.25]}$ Probe 4 (Fig. 7) containing no additional modifications at the salicylaldehyde units and ethylenediamine backbone was successfully applied for imaging of PPi in live HeLa cancer cells using confocal microscopy. ${ }^{25]}$ Cellular localization of the disassembled probe in mitochondria was confirmed by co-staining experiments with MitoTracker Red (MTR; Fig. 9). Evidence for a selective response toward endogenous PPi was obtained from glucose starvation and $\mathrm{KCN}$ inhibition. These conditions disable mitochondrial ATP production. ${ }^{[51]}$ In addition, inhibition of a plasma membrane PPi channel results in an increase of the intracellular PPi concentration and led to an increase in fluorescence. In contrast to staining experiments with probe $4, \mathrm{Fe}^{\mathrm{III}}$-salen complex $\mathbf{8}$ with a structurally modified salicylaldehyde and diamine backbone was not applicable for cellular assays.[20]

In addition to biological assays, complex $\mathbf{8}$ was also tested for sensing PPi alias E450 in foodstuff. In particular, the applicability was impressively demonstrated for PPi detection in baking powder.[20]

Addition of an aqueous sample of baking powder to compound 8 at $\mathrm{pH} 7.4$ ([Tris] $=10 \mathrm{mM}$ ) led to an increase of fluorescence at $500 \mathrm{~nm}$ (Fig. 10), whereas no spectral changes were observed in the presence of starch and $\mathrm{NaHCO}_{3}$, the other two main compounds of the commercial product.

\section{Conclusion}

In this mini review, we introduced the disassembly approach for polyoxophosphates (e.g. PPi, ATP) detection with metal-salen complexes. This approach was developed in the last five years in our laboratories. It is shown how structural modifications at different subunits of the metal complex affect properties and reactivity as well as sensitivity and selectivity of the probe. Careful structural optimization led to an improved system for selective detection of PPi in the presence of other potentially interfering polyoxophosphates and analytes. Applications for detecting PPi in cancer cells and foodstuff are demonstrated. Given the large potential for structural modifications of metal-salen complexes, we expect to develop improved analytical systems for PPi and other analytical targets in the future.

\section{Acknowledgements}

We would like to thank DSM Nutritional Products Ltd. for sponsoring the best poster award at the SCS Fall Meeting 2019. We would also like to thank Swiss Chemical Society for this opportunity and our project funding from Swiss National Science Foundation (SNF) (200021_169216).
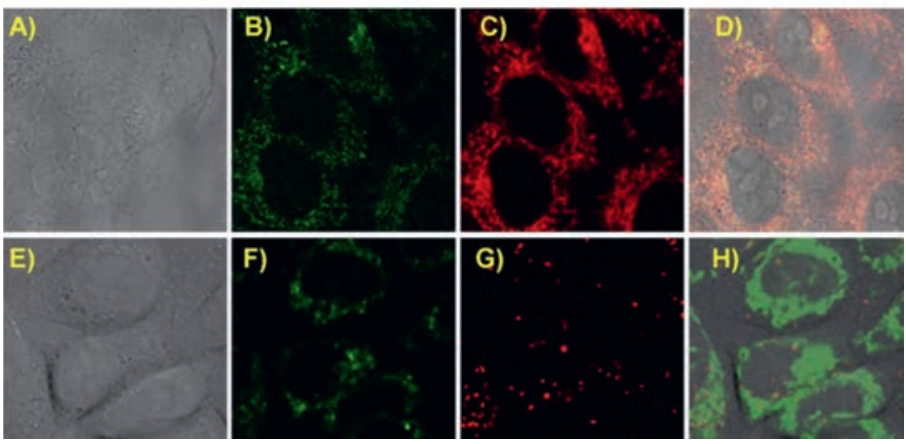

Fig. 9. Confocal fluorescence microscopy images of HeLa cells impregnated with $4(50 \mu \mathrm{M})$ and MTR (A-D, $150 \mathrm{~nm})$ or LysoTracker Red (E-H, $150 \mathrm{~nm})$; A), E) bright-field image of HeLa cells; B), F) images through green channel, C), G) images through red channel, and D), H) overlaid images (N. Kumari, H, Huang, H. Chao, G, Gasser, F. Zelder: 'A Disassembly Strategy for Imaging Endogenous Pyrophosphate in Mitochondria by Using an Fell-salen Complex', ChemBioChem. 2016, 17, 1213. Copyright Wiley-VCH Verlag GmbH \& Co. KGaA. Reproduced with permission. 


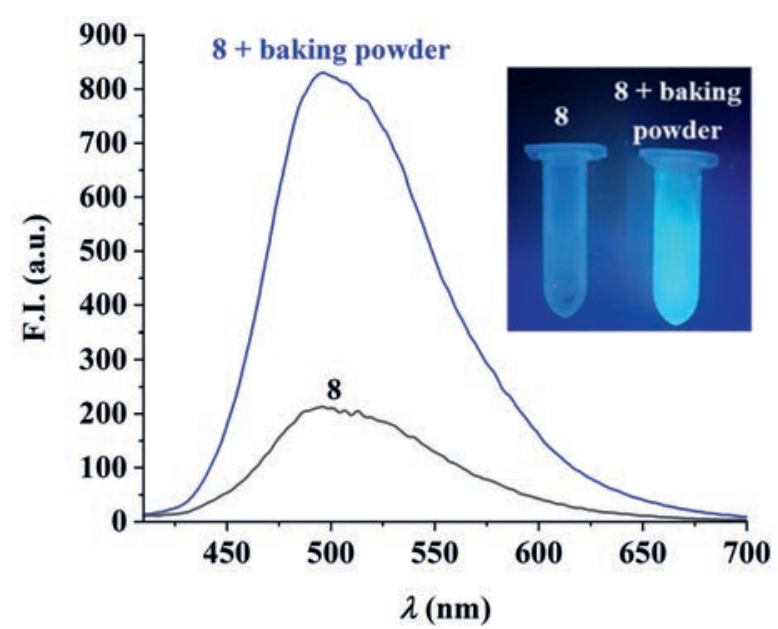

Fig. 10. Increase of fluorescence upon addition of an aqueous baking powder solution to $8\left(16 \mu \mathrm{M}, \lambda_{\text {ex }}=385 \mathrm{~nm}\right)$. Inset: Detection of PPi with $8(16 \mu \mathrm{M})$ in an aqueous baking powder solution using a laboratory UV lamp (adapted from ref. [20]).

Received: February 28, 2020

[1] L. Stryer, 'Biochemistry', Vol. 16, third ed., W. H. Freeman and Company, New York, 1988.

[2] A. E. Hargrove, S. Nieto, T. Zhang, J. L. Sessler, E. V. Anslyn, Chem. Rev. 2011, 111, 6603.

[3] C. F. Mason, 'Biology of Freshwater Pollution', Longman, New York, 1991

[4] 'Phosphorous in the Global Environment: Transfers, Cycles, and Managment', Ed. H. Thiessen, Wiley, New York, 1995.

[5] F. Loewus, 'Biosynthesis of phytate in food grains and seeds', CRC Press, Boca Raton, Florida USA, 2002.

[6] R. K. Gupta, S. S. Gangoliya, N. K. Singh, J. Food Sci. Technol. 2015, 52, 676.

[7] V. Kumar, A. K. Sinha, H. P. S. Makkar, K. Becker, Food Chem. 2010, 120, 945.

[8] V. Raboy, Phytochemistry 2003, 64, 1033.

[9] J. K. Heinonen, 'Biological Role of Inorganic Pyrophosphate', Kluwer Academic Publishers, Boston, 2001.

[10] G. D. Wright, M. Doherty, Ann. Rheum. Dis. 1997, 56, 586.

[11] S. Xu, M. He, H. Yu, X. Cai, X. Tan, B. Lu, B. Shu, Anal. Biochem. 2001, 299, 188.

[12] F. W. L. Tsui, Curr. Rheumatol. Rep. 2012, 14, 155.

[13] E. Ritz, K. Hahn, M. Ketteler, M. K. Kuhlmann, J. Mann, Dtsch. Arztebl. Int. 2012, 109, 49 .

[14] Institute of Medicine, 'Dietary Reference Intakes for Calcium, Phosphorus, Magnesium, Vitamin D and Fluoride', The National Academies Press, Washington, DC, 1997.

[15] R. Dhingra, L. M. Sullivan, C. S. Fox, T. J. Wang, R. B. D’Agostino, Sr, J. M. Gaziano, R. S. Vasan, Arch. Intern. Med. 2007, 167, 879.

[16] U. Trautvetter, B. Ditscheid, G. Jahreis, M. Glei, Nutrients 2018, 10, 171.

[17] H. J. Jessen, 'Phosphate Labeling and Sensing in Chemical Biology', Springer International Publishing, Switzerland, 2017.

[18] S. Pal, T. K. Ghosh, R. Ghosh, S. Mondal, P. Ghosh, Coord. Chem. Rev. 2020, 405, 213128

[19] F. Zelder, Chem. Commun. 2015, 51, 14004.
[20] P. Yadav, M. Jakubaszek, B. Spingler, B. Goud, G. Gasser, F. H. Zelder, Chem. Eur. J. 2020, https://doi.org/10.1002/chem.201905686.

[21] D. A. Smyth, C. C. Black, Plant Physiol. 1984, 75, 862.

[22] J. Edwards, T. A. Rees, P. M. Wilson, S. Morrell, Planta 1984, 162, 188.

[23] S. Lee, K. K. Y. Yuen, K. A. Jolliffe, J. Yoon, Chem. Soc. Rev. 2015, 44, 1749.

[24] S. K. Kim, D. H. Lee, J.-I. Hong, J. Yoon, Acc. Chem. Res. 2009, 42, 23.

[25] N. Kumari, H. Huang, H. Chao, G. Gasser, F. Zelder, ChemBioChem. 2016, $17,1211$.

[26] N. Kumari, F. Zelder, Chem. Commun. 2015, 51, 17170.

[27] R. B. Stockbridge, R. Wolfenden, J. Biol. Chem. 2011, 286, 18538.

[28] H. N. Po, N. M. Senozan, J. Chem. Educ. 2001, 78, 1499.

[29] O. F. Ikotun, N. Marino, P. E. Kruger, M. Julve, R. P. Doyle, Coord. Chem. Rev. 2010, 254, 890 .

[30] T. P. Haromy, W. B. Knight, D. Dunaway-Mariano, M. Sundaralingam, Acta Cryst. 1984, 40, 223.

[31] F. Capitelli, B. El Bali, R. Essehli, M. Lachkar, V. Valentini, G. Mattei, J. Taraba, Z. Zak, Z. Kristallogr. 2006, 221, 649.

[32] A. Gharbi, A. Jouini, J. Chem. Crystallogr. 2004, 34, 727.

[33] A. Gharbi, A. Jouini, M. T. Averbuch-Pouchot, A. Durif, J. Solid State Chem. 1994, 111,330 .

[34] R. J. Mishur, C. Zheng, T. M. Gilbert, R. N. Bose, Inorg. Chem. 2008, 47, 7972.

[35] D. H. Lee, J. H. Im, S. U. Son, Y. K. Chung, J.-I. Hong, J. Am. Chem. Soc. 2003, 125, 7752 .

[36] O. F. Ikotun, N. G. Armatus, M. Julve, P. E. Kruger, F. Lloret, M. Nieuwenhuyzen, R. P. Doyle, Inorg. Chem. 2007, 46, 6668.

[37] E. W. Ainscough, A. M. Brodie, J. D. Ranford, J. M. Waters, K. S. Murray, Inorg. Chim. Acta 1992, 197, 107.

[38] N. Herron, D. L. Thorn, R. L. Harlow, G. W. Coulston, J. Am. Chem. Soc. 1997, 119, 7149.

[39] R. P. Doyle, M. Nieuwenhuyzen, P. E. Kruger, Dalton Trans. 2005, 3745.

[40] N. Marino, T. F. Mastropietro, D. Armentano, G. De Munno, R. P. Doyle, F. Lloret, M. Julve, Dalton Trans. 2008, 5152.

[41] P. Heikinheimo, J. Lehtonen, A. Baykov, R. Lahti, B. S. Cooperman, A. Goldman, Structure 1996, 4, 1491.

[42] B. Nguyen, E. Anslyn, Coord. Chem. Rev. 2006, 250, 3118.

[43] D. H. Lee, S. Y. Kim, J.-I. Hong, Angew. Chem. Int. Ed. 2004, 43, 4777.

[44] H. K. Cho, D. H. Lee, J.-I. Hong, Chem. Commun. 2005, 13, 1690.

[45] M. J. McDonough, A. J. Reynolds, W. Y. G. Lee, K. A. Jolliffe, Chem. Commun. 2006, 28, 2971.

[46] R. Martínez-Máñez, F. Sancenón, Chem. Rev. 2003, 103, 4419.

[47] D. H. Vance, A. W. Czarnik, J. Am. Chem. Soc. 1994, 116, 9397.

[48] S. Bhowmik, B. N. Ghosh, V. Marjomäki, K. Rissanen, J. Am. Chem. Soc. 2014, 136, 5543 .

[49] H. S. Jung, J. H. Han, Z. H. Kim, C. Kang, J. S. Kim, Org. Lett. 2011, 13, 5056.

[50] J. Liu, J. Cheng, X. Ma, X. Zhou, H. Xiang, Res. Chem. Intermed 2016, 42, 5027.

[51] A. I. Tarasov, G. A. Rutter, Methods Enzymol. 2014, 542, 289.

\section{License and Terms}

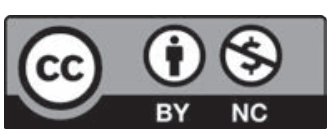

This is an Open Access article under the terms of the Creative Commons Attribution License CC BY_NC 4.0. The material may not be used for commercial purposes.

The license is subject to the CHIMIA terms and conditions: (http:// chimia.ch/component/sppagebuilder/?view = page \&id=12).

The definitive version of this article is the electronic one that can be found at doi:10.2533/chimia.2020.252 